\title{
Balkanologie
}

Balkanologie Revue d'études pluridisciplinaires

Vol. $15 n^{\circ} 1 \mid 2020$

Mémoires performatives : faire des passés et des présents

\section{Hommage au Professeur}

Iulia Hasdeu, Bianca Botea et Alec Balasescu

\section{(2) OpenEdition}

Journals

\section{Édition électronique}

URL : https://journals.openedition.org/balkanologie/2463

DOI : 10.4000/balkanologie.2463

ISSN : 1965-0582

Éditeur

Association française d'études sur les Balkans (Afebalk)

Référence électronique

Iulia Hasdeu, Bianca Botea et Alec Balasescu, «Hommage au Professeur », Balkanologie [En ligne], Vol. $15 n^{\circ} 1$ | 2020, mis en ligne le 01 juin 2020, consulté le 05 août 2021. URL : http://

journals.openedition.org/balkanologie/2463; DOI : https://doi.org/10.4000/balkanologie.2463

Ce document a été généré automatiquement le 5 août 2021

(C) Tous droits réservés 


\title{
Hommage au Professeur
}

\author{
Iulia Hasdeu, Bianca Botea et Alec Balasescu
}

1 «Vintilă n'est plus là » [Vintilă nu mai e] a été l'intitulé spontanément proposé par un petit groupe sur un réseau social, dont nous faisions partie. Étudiants de Vintilă Mihăilescu dans les années 1990, exerçant aujourd'hui l'anthropologie en diaspora, nous nous sommes rassemblés virtuellement, touchés par le poids insoutenable de la nouvelle de sa disparition.

2 C'était le 22 mars 2020 , dans sa $70^{\text {ème }}$ année, après une lutte longue et acharnée contre la maladie. De cette lutte témoigne un excellent essai anthropologique sur l'hôpital et la condition du patient dans le système de santé, ainsi que sur la remise en question de la dualité rationaliste corps-esprit, În căutarea corpului regăsit : o ego-analiză a spitalului [À la recherche du corps retrouvé : une égo-analyse de l'hôpital] (Polirom, 2019). Dans ce dernier ouvrage, comme ailleurs dans ses écrits, Vintilă Mihăilescu considère que toute expérience est source de connaissance à partager généreusement avec les autres, il regarde la mort en face en apportant un hommage à la vie et au corps « en chair et en os ", qu'il soit sain ou malade.

3 En plein confinement, alors qu'il était impossible de se rendre aux funérailles, plus de 800 messages, des souvenirs et des photos ont circulé pendant trois jours sur une page créée ad hoc sur le même réseau social. La plupart de ces messages ont été envoyés par des personnes jeunes, en particulier des ancien.ne.s étudiant.e.s du Professeur, comme nous nous l'appelions en nous adressant à lui («Monsieur le professeur»), alors que dans les discussions entre nous il était « Vintilă ».

4 Ainsi, en deçà et au-delà des nombreux livres et articles publiés, des titres, des fonctions prestigieuses, et même au-delà du rôle de fondateur de l'anthropologie récente en Roumanie, Vintilă Mihăilescu a marqué par son professorat. Et encore, ce n'est pas tant parce qu'il a mis sur pied le premier programme de master en anthropologie sociale à l'Université de Bucarest en 1998. Ce n'est pas non plus parce que chez lui l'art du conteur devenait méthodologie et parce que parler de la construction des maisons et du chou farci n'était pas un simple détour ou une joute oratoire, mais l'essence même d'un savoir curieux, patient et gai. 
5 Le Professeur était une référence surtout parce que, à l'image d'un maitre spirituel, sachant manier l'humour et l'(auto)ironie comme aucun autre, il a été pour plusieurs générations d'étudiants l'initiateur in situ de leurs premiers entretiens, de questionnements quant aux difficultés de communication, du «croisement» des regards ${ }^{1}$, aussi bien que de l'analyse et de l'exercice de l'écriture. La particularité de son approche pédagogique, voire la valeur intrinsèque de celle-ci, consiste, en pratique, dans les terrains collectifs organisés avec des groupes de jeunes étudiants. Ces séjours de terrain au début des années 1990, dans des régions rurales en Roumanie et ultérieurement dans des villes mais aussi dans d'autres pays européens, ont engendré des collaborations interuniversitaires importantes. Ils ont constitué l'occasion d'une double réflexion à la fois portée sur les phénomènes observés en documentant une société en prise avec des transformations rapides et ouvrant vers des perspectives méthodologiques alternatives à la traditionnelle immersion solitaire dans le terrain.

Pour la jeunesse universitaire de la Roumanie d'aujourd'hui, les coopérations internationales sont une évidence non questionnée. Pour les jeunes chercheurs débutant juste après la chute du mur de Berlin, ces coopérations représentaient un travail de conception et de mise en place difficile et inédit, en même temps qu'une chance inespérée d'étudier dans des lieux prestigieux. Dans le sillage de cette construction commencée il y a plus de 25 ans par le Professeur, une partie de ces étudiant.e.s se consacrent aujourd'hui à la recherche et à l'enseignement.

7 Nous souhaitons rappeler ici notre reconnaissance et notre admiration envers le Professeur et nous souvenir de lui comme d'un aventurier sur le grand fleuve de la vie, d'un guide spirituel épicurien et d'un adorateur amusé des rituels qui célèbrent les plaisirs quotidiens et la joie d'être ensemble; un pédagogue qui a su en faire une expérience de formation à l'anthropologie, singulière et inoubliable. Nous nous souvenons aussi de Vintilă, celui qui aimait la commensalité, qui dansait et palabrait, qui aimait jouer à la pétanque sur une plage et plonger les coins de sa moustache dans une bière fraiche. En ultime hommage, nous sourions ensemble à l'idée que le Professeur aurait certainement transformé en plaisir cet acte de connaissance de la/sa mort au temps de la COVID-19, de sa dématérialisation et de l'intensité spirituelle collective qu'elle engendre. Même s'il n'est plus de ce monde avec sa barbe et ses lunettes, avec sa démarche à la Charlot et son air post-hippie, Vintilă continuera de vivre en nous.

\section{NOTES}

1. Nous faisons référence ici au dispositif intitulé «terrains croisés", impulsé par Vintilă Mihăilescu et ses collègues de Belgique et d'Italie, Marianne Mesnil et Cristina Papa. À travers ce dispositif, une équipe d'étudiants de ces trois pays a été accompagnée lors d'une expérience de recherche commune sur des terrains roumains, français et italiens. Sur cette pratique de terrain, voir par exemple l'article: IONESCU-MUSCEL Adina, MAHIEU Stéphanie, «Par-delà le clivage est/ ouest: l'expérience des terrains croisés », Balkanologie, vol. IV, $\mathrm{n}^{\circ} 2,2000$, en ligne: http:// journals.openedition.org/balkanologie/342. 


\section{AUTEURS}

IULIA HASDEU

Haute école de travail social, Genève, Suisse

BIANCA BOTEA

Université Lyon 2, France

\section{ALEC BALASESCU}

Royal Roads University, Victoria, Canada 